\title{
Electrocatalytic reduction of molecular oxygen by mononuclear and binuclear cobalt phthalocyanines
}

\author{
Michael R. Hempstead, ${ }^{1}$ A. B. P. Lever, ${ }^{1}$ And Clifford C. Leznoff \\ Department of Chemistry, York University, North York, Ont., Canada M3J IP3
}

\begin{abstract}
Michael R. Hempstead, A. B. P. Lever, and Clifford C. Leznoff. Can. J. Chem. 65, 2677 (1987).
Investigations of the electrocatalytic activity of mononuclear and binuclear cobalt phthalocyanines for the reduction of molecular oxygen established that the latter compounds are more effective catalysts than the corresponding mononuclear species. A correlation between the half-bandwidths for the $Q$ band of these species and their catalytic efficiency, expressed as a kinetically-limited current, suggests that the increase in activity may be attributed to electronic coupling between the phthalocyanine rings.
\end{abstract}

\begin{abstract}
Michael R. Hempstead, A. B. P. Lever et Clifford C. Leznoff. Can. J. Chem. 65, 2677 (1987).
Des études sur l'activité électrocatalytique des phtalocyanines de cobalt mononucléaires et binucléaires pour la réduction de l'oxygène moléculaire ont permis d'établir que les derniers composés sont des catalyseurs plus efficaces que les espèces mononucléaires correspondantes. Une corrélation entre les demi-largeurs des bandes $Q$ de ces espèces et leur efficacité catalytique, exprimée sous la forme de courant limite cinétique, suggère que l'augmentation de l'activité peut être attribuée au couplage électronique entre les cycles phtalocyanines.
\end{abstract}

[Traduit par la revue]

\section{Introduction}

If a fuel cell is to operate efficiently, a catalyst must be embedded in the cathode to accelerate the reduction of oxygen gas. This catalyst must be capable of withstanding the operating conditions of the fuel cell (strong acid or base, fairly high temperatures), for long periods of time, without loss of activity. Platinum is commonly used as a fuel cell catalyst, but is expensive, representing some $10 \%$ of the total fuel cell cost. Catalysts which are more effective and less expensive are needed, if fuel cell applications are to become viable.

Many mononuclear metal porphyrins act as electrocatalysts (1-21) but the work of Collman and Anson (22-28) and Chang and co-workers (29-35) has revealed that certain binuclear porphyrins are much more effective. Similarly, mononuclear phthalocyanines of iron and cobalt are effective (36-50), but some ill-characterised "dimeric" and polymeric phthalocyanines appear more effective (51-62). Savy and co-workers (54-56) performed ESCA, esr, Mössbauer and optical spectroscopic studies to establish correlations between the spectroscopic properties of polymeric and monomeric iron phthalocyanines and the electrocatalytic activity of these species towards oxygen reduction. We consider here a correlation between the optical spectra of a series of well-characterized mono- and binuclear cobalt phthalocyanines and their electrocatalytic activity.

The binuclear porphyrins studied by Collman and Anson are too fragile for long-term use under fuel cell conditions and therefore our studies have been directed towards thermally more stable binuclear phthalocyanine compounds. We have recently reported (63-65) a series of binuclear phthalocyanine complexes of the general formula [M-tri(neopentoxy)phthalocyanine $]_{2}$ (bridge) where the bridge may contain $1,2,4$, or 5 atoms, and where $\mathrm{M}$ may be $\mathrm{H}_{2}, \mathrm{Cu}$, or Co. The three neopentoxy groups are randomly distributed in the 4 or 5 positions of the three unbridged benzene rings, providing solubility in many organic solvents, e.g., toluene, o-dichlorobenzene, and dichloroethane, but generally not acetone and ethanol.

Of relevance to this presentation are the following species, with their abbreviations (the number in parentheses is the number of bridging atoms connecting the two phthalocya-

\footnotetext{
'Author to whom correspondence may be addressed.
}

nine rings): CoTNPc, 2,9,16,23-tetraneopentoxyphthalocyanatocobalt(II). This is the mononuclear control molecule. $\mathrm{O}(1)\left[\mathrm{Co} \operatorname{TrNPc}_{2}\right.$, bis-2-(9,16,23-trineopentoxyphthalocyaninylcobalt(II))ether; two phthalocyanine rings linked by a single oxygen (ether) bridge. $\mathrm{C}(2)[\mathrm{CoTrNPc}]_{2}, 1,2-$ bis- $2^{\prime}-\left(9^{\prime}, 16^{\prime}, 23^{\prime}\right.$ trineopentoxyphthalocyaninylcobalt(II))ethane; two phthalocyanine rings linked by an ethane $-\mathrm{CH}_{2} \mathrm{CH}_{2}-$ bridge. Cat(4) $[\mathrm{CoTrNPc}]_{2}, 1,2$-bis-2'-( $\left(9^{\prime}, 16^{\prime}, 23^{\prime}\right.$-trineopentoxyphthalocyaninoxycobalt(II))benzene; two phthalocyanine rings linked by a catechol $-\mathrm{O}-\mathrm{C}_{6} \mathrm{H}_{4}-\mathrm{O}-$ bridge. EtMeO(5)[CoTrNPc $]_{2}$, 1,3-bis-2'-(9',16',23' -trineopentoxyphthalocyaninoxycobalt(II)) 2-ethyl-2-methylpropane; two phthalocyanine rings linked by $\mathrm{a}-\mathrm{OCH}_{2} \mathrm{C}(\mathrm{Et})(\mathrm{Me}) \mathrm{CH}_{2} \mathrm{O}-$ bridge.

Earlier investigations of the metal-free analogues of these species (66) established properties of these compounds which are relevant to the observations reported here. These properties are as follows. (i) In condensed phases (frozen solution glass, Nujol mull, etc.), these complexes may exhibit intermolecular aggregation. In dilute solution, $<5 \times 10^{-5} \mathrm{M}$, intermolecular aggregation is generally absent (67). (ii) Some binuclear phthalocyanines may close upon themselves ("clamshell" behaviour) to aggregate via cofacial intramolecular aggregation. Specifically, of the metal-free species, only $\mathrm{Cat}(4)\left[\mathrm{TrNPcH}_{2}\right]_{2}$ and $\mathrm{EtMeO}(5)\left[\mathrm{TrNPCH}_{2}\right]_{2}$ are capable of such intramolecular aggregation. Such species exist in a dynamic equilibrium with "open" conformations. (iii) The electronic spectra of the metal-free species show evidence of the coupling of the transition moments on each phthalocyanine ring (66). Thus direct through space coupling is observed in the cofacial conformations, giving rise to a blue shift in the $\mathrm{Q}$ and Soret absorptions. However, a blue shift is also observed in the other metal-free species, as a consequence of coupling through space (or through the bridge) in "open", non-aggregated conformations.

Note that electronic coupling is more readily detected in the electronic spectra of binuclear phthalocyanine species, relative to comparable porphyrin species, because the visible region transition moments are much larger in the former case (68).

\section{Experimental}

The species $\mathrm{Co}(\mathrm{II}) \mathrm{TNPc}(64)$, EtMeO(5) $\left[\mathrm{Co}(\mathrm{II}) \mathrm{TrNPc}_{2}\right.$ (64), $\mathrm{C}(2)\left[\mathrm{Co}(\mathrm{II}) \mathrm{TrNPc}_{2} \text { (65), Cat(4)[Co(II) TrNPc }\right]_{2}$ (65), and $\mathrm{O}(1)$ $[\mathrm{Co}(\mathrm{II}) \mathrm{TrNPc}]_{2}(69)$ were prepared by literature routes. Aldrich Gold 
Label o-dichlorobenzene (DCB) was used without further purification and Fisher certified $1 \mathrm{~N}$ sodium hydroxide was diluted as required for the aqueous studies. Water was purified by double-distillation over $\mathrm{KMnO}_{4}$ followed by passage through a Barnstead organic removal cartridge and two Barnstead mixed resin ultrapure cartridges. Stressannealed pyrolytic graphite (SAPG) and ordinary pyrolytic graphite (OPG), obtained from Union Carbide, were used as electrode materials. The graphite was mounted in Teflon to expose a circular area of $0.490 \mathrm{~cm}^{2}$ for the SAPG electrode and $0.493 \mathrm{~cm}^{2}$ for the OPG electrode. Before each experiment, the OPG electrode surface was cleaned by successive polishings with $1.0 \mu \mathrm{m}, 0.3 \mu \mathrm{m}$, and $0.05 \mu \mathrm{m}$ alumina (Linde) suspended in water on Metron polishing cloth. Argon gas (Linde) was purified by passage through heated copper filings, anhydrous $\mathrm{CaSO}_{4}$ (Drierite), molecular sieves (BDH Type 3A), and glass wool. Oxygen gas (Linde) was purified by passage through anhydrous $\mathrm{CaSO}_{4}$, NaOH pellets (AnalaR analytical grade), anhydrous $\mathrm{CaSO}_{4}$, molecular sieves, and glass wool. Tetrabutylammonium perchlorate (TBAP) (Eastman Kodak) was recrystallized from absolute ethanol and dried in a vacuum oven at $50^{\circ} \mathrm{C}$ for 2 days. Potential scans were performed with a Pine Instruments RD3 potentiostat and the rotation studies with a Pine Instruments PIR rotator. The cell for the adsorption experiments employed a medium frit to separate a silver wire quasi-reference electrode from the main chamber containing the OPG working electrode and a platinum wire counter electrode. The cell for the aqueous studies comprised a separate chamber for each electrode with a Luggin capillary extending from the reference chamber to the proximity of the OPG surface. For all aqueous experiments, the potential was measured versus a saturated calomel electrode (sce).

Phthalocyanine solutions were prepared in DCB with $0.1 M$ TBAP as supporting electrolyte, such that the concentration was ca. $10 \mu M$ with respect to the TNPc unit. These solutions were purged with argon for about an hour before scanning the working electrode at a rate of $100 \mathrm{mV} / \mathrm{s}$ over the range 0.00 to $+1.00 \mathrm{~V}$ versus the silver wire. Adsorbed layers on OPG or SAPG electrodes were obtained by cycling until the anodic and cathodic peak currents associated with the adsorbed species remained constant over $5 \mathrm{~min}$ of continuous scanning. When this condition was satisfied, the adsorbed layer was assumed to have reached a steady coverage. Scans at various rates were then recorded to determine the surface coverage (vide infra).

The catalytic efficiency of the various phthalocyanine compounds was investigated with the adsorbed species on the OPG electrode. This modified electrode was removed from the phthalocyanine solution, washed with ethanol, then with water, and finally placed in the cell for the aqueous studies. The $0.10 \mathrm{M} \mathrm{NaOH}$ solution in this cell had been purged with oxygen for several hours to ensure saturation. The electrode was then scanned over the range 0.00 to $-1.00 \mathrm{~V}$ versus sce at a rate of $10 \mathrm{mV} / \mathrm{s}$ for rotation rates ranging from 400 to $10000 \mathrm{rpm}$. After each scan, the electrode was held at $0.00 \mathrm{~V}$ for $1 \mathrm{~min}$ to permit the rotation rate to be changed for the next scan.

\section{Results}

\section{(l) Adsorption studies}

Some preliminary adsorption experiments were performed on a SAPG electrode to determine the electronic nature and orientation of the adsorbed species. The cyclic voltammograms for a solution of $2.5 \times 10^{-5} M$ CoTNPc in DCB and $0.1 M$ TBAP studied at a SAPG working electrode, as shown in Fig. 1, display two couples in close proximity. Following deconvolution of these waves, ${ }^{2}$ a plot (Fig. $2 A$ ) of cathodic peak current, $i_{\mathrm{p}, \mathrm{c}}$, versus scan rate, $v$, for couple I $(R=0.999)$ and a

\footnotetext{
${ }^{2}$ The cathodic waves for these couples were deconvoluted by subtracting the background from a neat DCB solution to obtain a baseline followed by construction of a symmetric wave about the peak of couple $I$. The contribution of the symmetric wave in the region of mixed currents was subtracted from the observed response to obtain the current associated with couple II. Complete details of this deconvolution are described in ref. 1.
}

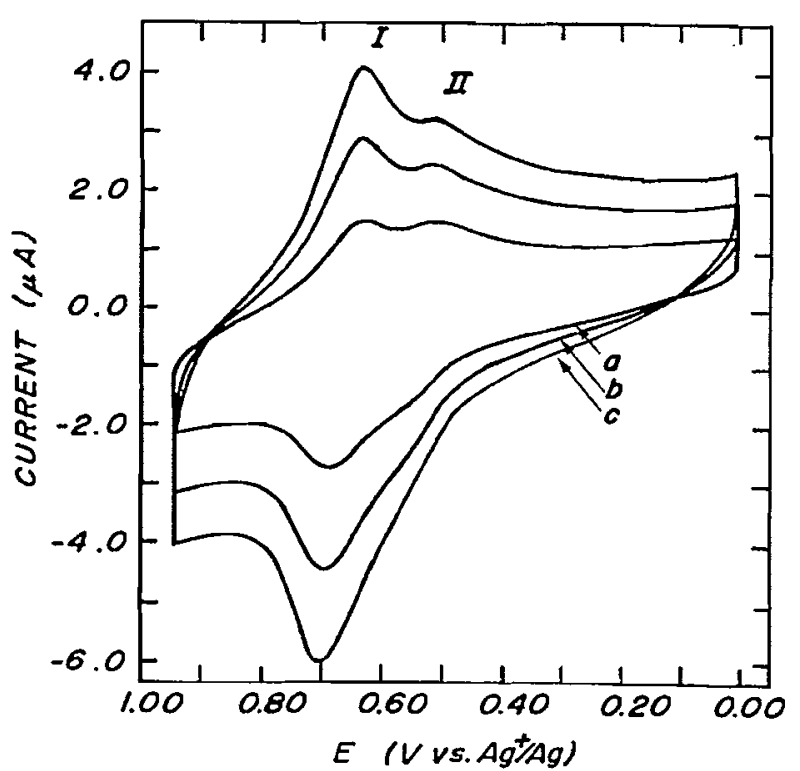

FIG. 1. Cyclic voltammograms at scan rates of $(a) 50 \mathrm{mV} / \mathrm{s},(b)$ $100 \mathrm{mV} / \mathrm{s}$, and $(c) 150 \mathrm{mV} / \mathrm{s}$ for $2.5 \times 10^{-5} M$ CoTNPc in DCB and $0.1 M$ TBAP under argon at a SAPG working electrode. Couples I and II are both associated with the $[\mathrm{Co}(\mathrm{II}) \mathrm{TNP}(-1)]^{+} / \mathrm{Co}$ (II)TNPc $(-2)$ process. The nature of these couples is investigated more fully in Fig. 2.

plot (Fig. $2 B$ ) of $i_{\mathrm{p}, \mathrm{c}}$ versus $\sqrt{v}$ for couple II $(R=0.998)$ indicated that these couples were adsorption and diffusion processes (71), respectively. From the relative positions of couples I and II, it follows that the adsorbed species binds most strongly in the reduced form associated with couple II (72), although the presence of a reductive adsorption wave indicates that the oxidized form associated with this couple also binds to the electrode. Couple II is associated with the ligand process $[\mathrm{Co} \text { (II)TNPc }(-1)]^{+} / \mathrm{Co}(\mathrm{II}) \mathrm{TNPc}(-2)(73)$ and therefore CoTNPc binds to the graphite surface most strongly as $\mathrm{Co}(\mathrm{II}) \mathrm{TNPc}(-2)$. The binding between the CoTNPC and the SAPG electrode can be explained by $\pi-\pi$ interactions between the phthalocyanine ring and the graphite lattice, if the CoTNPc is adsorbed flat to the SAPG surface. This mode of adsorption has also been suggested in a similar investigation (41) by Yeager and co-workers who studied cobalt tetrasulphonate phthalocyanine (CoTSPc).

In addition to the electronic nature and orientation of the adsorbed molecule, the extent of coverage of the catalyst on the electrode surface must be known. Quantitative analysis requires the selection of an appropriate adsorption isotherm to describe the cyclic voltammetric response of the adsorbate. An adsorption isotherm describes the relationship between the concentrations of the adsorbate in the adsorption layer and in the bulk phase from which the adsorption takes place. Appropriate isotherms may also yield information about interactions between molecules in the adsorption layer.

The Langmuir isotherm was used to analyse the adsorption of CoTNPc on a SAPG electrode. This isotherm applies to systems in which there are no interactions between the adsorbed molecules (72). For systems which satisfy these conditions, the value of $n$ may be calculated from the peak-width-at-halfheight, $W_{1 / 2}$, from the expression

[1] $n=\frac{2 R T}{W_{1 / 2} F} \ln (3+2 \sqrt{2})$ 

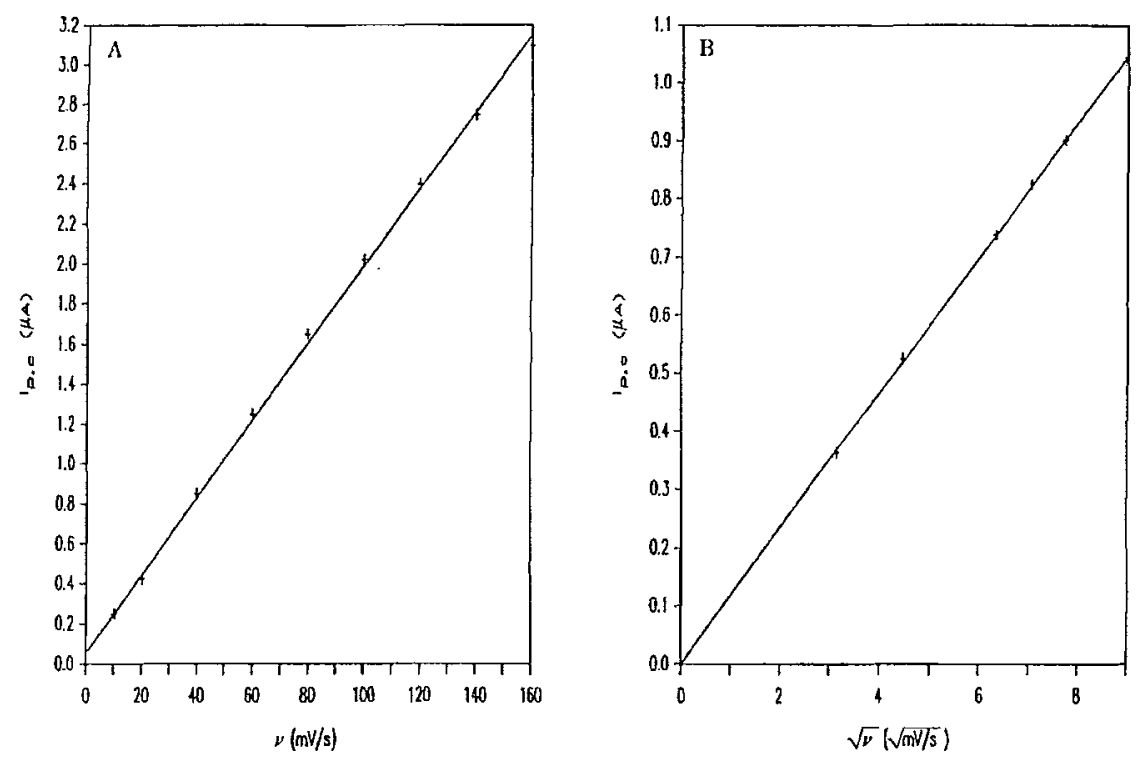

FiG. 2. Plots of the dependence of cathodic peak current with scan rate for $(A)$ couple I and $(B)$ couple II, as designated in Fig. $1\left(2.5 \times 10^{-5} M\right.$ CoTNPc in DCB and 0.1 $M$ TBAP at a SAPG working electrode).

The average value of $n$ calculated in this fashion was $1.00 \pm$ 0.02 in excellent agreement with our expectation of a oneelectron process. By calculating the charge under the adsorption peak and assuming the area of a phthalocyanine molecule, $A_{\mathrm{pc}}$, is $200 \AA^{2}(41)$, the coverage of CoTNPc on a SAPG electrode was determined to be about $0.30 \pm 0.1$ monolayers. This low level of coverage is consistent with another study (41) in which CoTSPc adsorbed on SAPG to the extent of 0.4 monolayers.

Since a coverage of between one and two monolayers was desired for these oxygen reduction studies, SAPG was not used for these investigations. (Recent studies have established a method for obtaining a coverage of one monolayer on SAPG which will be employed in later investigations.) Yeager and co-workers (42) found that CoTSPc could be adsorbed on OPG to about four times the coverage on SAPG; the greater adsorption on the OPG electrode was attributed to a higher density of surface defects assumed to be critical to adsorption (74). Adsorption experiments with CoTNPc and an OPG electrode did show enhanced adsorption, as shown in Fig. 3 This increased adsorption affects the cyclic voltammograms in many ways. The most readily apparent effect is the loss of the diffusion wave which had been observed in conjunction with an adsorption wave when using SAPG. Since the adsorption wave overwhelms the diffusion wave under the conditions employed for this experiment (71), later calculations of surface coverage disregard contributions from diffusion and treat this as a pure adsorption process. The other noticeable effect in Fig. 3 is the large peak separation observed at higher scan rates. This probably arises from the larger currents observed in this scan and the high $i R$ drop in these DCB solutions.

The adsorption studies with the OPG electrode were analysed with the Langmuir isotherm which gave an average $n$ value of $0.72 \pm 0.04$, suggesting that the use of the Langmuir isotherm was not appropriate for this system. An altemate choice, the Frumkin isotherm $(75-78)$ is useful for systems in which there are interactions between adsorbed molecules. A recent investigation (78) of several isotherms suggests that the Frumkin isotherm is most appropriate for electrochemical processes involving the adsorption of organic compounds. According to the Frumkin isotherm, the peak current and the value of $n$ are

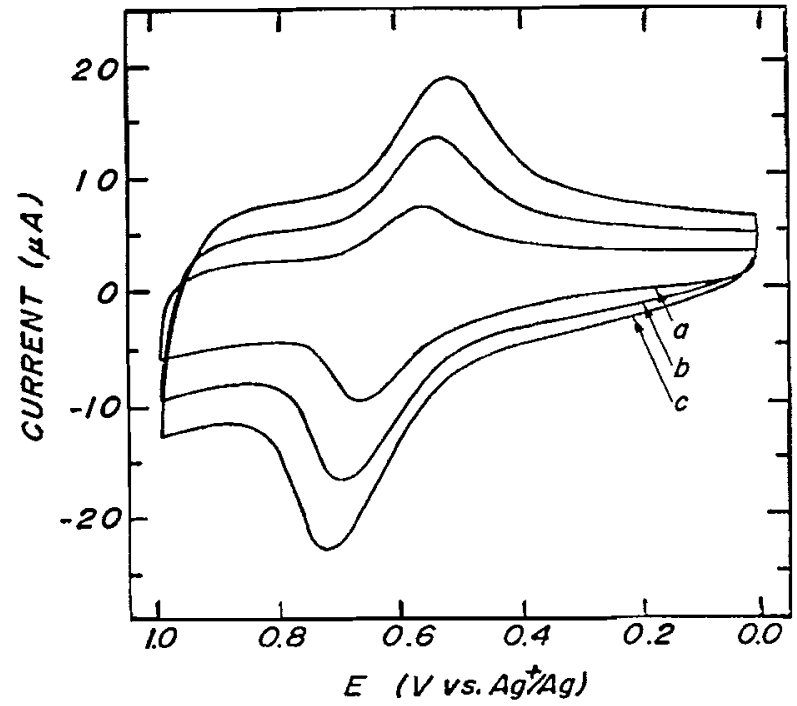

Fig. 3. Cyclic voltammograms at scan rates of $(a) 50 \mathrm{mV} / \mathrm{s},(b)$ $100 \mathrm{mV} / \mathrm{s}$, and $(c) 150 \mathrm{mV} / \mathrm{s}$ for $1.0 \times 10^{-5} M \mathrm{TNPcCo}$ in DCB and $0.1 M$ TBAP at an OPG working electrode. The waves shown here are associated with the $[\mathrm{Co}(\mathrm{II}) \mathrm{TNPC}(-1)]^{+} / \mathrm{Co}(\mathrm{II}) \mathrm{TNPc}(-2)$ couple.

given by the expressions (77)

[2] $i_{\mathrm{p}}=\frac{n^{2} F^{2} A \Gamma \nu}{R T(4-2 r \Gamma)}$

[3] $n=\frac{2 R T}{W_{1 / 2} F}\left[\ln P-r \Gamma \frac{P-1}{P+1}\right]$

where $r$ is an interaction parameter $\left(\mathrm{cm}^{2} / \mathrm{mol}\right), \Gamma$ is the surface concentration of the adsorbed species $\left(\mathrm{mol} / \mathrm{cm}^{2}\right)$, and $P$ is given by

[4] $P=3-r \Gamma+\left(r^{2} \Gamma^{2}-6 r \Gamma+8\right)^{1 / 2}$

Repulsive interactions are denoted by negative values of $r$ while stabilizing interactions are denoted by positive values of $r$. If the interactions between adsorbed molecules are repulsive, the wave broadens and the peak decreases, but if the interactions 
TABLE 1. Average values of $\theta$ and $r \Gamma$ for an OPG electrode modified with CoTNPc or one of its binuclear derivatives

\begin{tabular}{lcc}
\hline \multicolumn{1}{c}{ Compound } & $\theta$ & $r \Gamma$ \\
\hline CoTNPc & $1.4 \pm 0.4$ & $-0.77 \pm 0.14$ \\
$\mathrm{O}(1)[\mathrm{CoTrNPc}]_{2}$ & $1.3 \pm 0.4$ & $-1.36 \pm 0.11$ \\
$\mathrm{C}(2)[\mathrm{CoTrNPc}]_{2}$ & $1.8 \pm 0.1$ & $-0.87 \pm 0.13$ \\
${\text { Cat(4)[CoTrNPc }]_{2}}_{\text {EtMeO(5)[CoTrNPc }]_{2}}$ & $2.2 \pm 0.2$ & $-0.88 \pm 0.06$ \\
EtM & $2.2 \pm 0.4$ & $-0.85 \pm 0.01$ \\
\hline
\end{tabular}

are attractive, the wave narrows and the peak increases. If the interaction parameter is zero, then the Frumkin isotherm expressions simplify to those given by the Langmuir isotherm.

The cyclic voltammograms from the adsorption studies on OPG displayed waves which were broader and more rounded than those observed for the SAPG experiments. This change in waveshape indicates that at these higher coverages, repulsive interactions exist between molecules adsorbed on the electrode surface. The voltammograms which had been analysed by the Langmuir isotherm to give an average $n$ value of $0.72 \pm 0.04$ when analysed by the Frumkin isotherm yielded $0.93 \pm 0.03$ in much better agreement with the expected value of unity.

Average values of the dimensionless parameters $r \Gamma$ and the average surface coverage, $\theta$ (where $\theta=\Gamma A_{\mathrm{pc}}$ ), are presented in Table 1 for an OPG electrode modified with CoTNPc or one of its binuclear derivatives. The surface coverage calculations for the binuclear compounds used the same area approximation per phthalocyanine unit as had been used for CoTNPc since these calculations were designed to estimate the number of cobalt atoms on the electrode surface, not the number of phthalocyanine molecules. As a means of clarifying this point, consider the following example. If a value of 2.0 is calculated for $\theta$, this could indicate that the electrode is covered by two monolayers of the mononuclear species, two layers of a binuclear species in an "open" configuration, or one layer of a binuclear species in a cofacial configuration. Consideration of steric restraints in these molecules and the behaviour of these species in solution is required to infer the manner in which these molecules adsorb on the electrode surface.

The $\theta$ value of $1.4 \pm 0.4$ for CoTNPc-modified OPG electrodes is most likely indicative of a coverage of one monolayer. The reported $\theta$ may be somewhat high as it is based on the geometric area of the electrode and does not account for the inherent roughness of the surface. It is improbable that a second layer forms on the surface since none of the adsorbate is lost after washing and transferring to an aqueous solution. A weakly bound second layer of CoTSPc on OPG has been reported (74), but it was readily removed by washing.

The average coverage for the molecule $\mathrm{O}(1)[\mathrm{CoTrNPc}]_{2}$ was $1.3 \pm 0.4$, which is quite similar to that found for CoTNPc. The adsorption of $\mathrm{O}(1)[\mathrm{CoTrNPc}]_{2}$ was anticipated to be similar to that of CoTNPc because this binuclear species can only exist in an "open" conformation. The $\mathrm{O}(1)[\mathrm{CoTrNPc}]_{2}$ molecule would adsorb with one ring flat on the OPG surface while the other ring lies at some oblique orientation. The ring in the oblique orientation would give this surface a highly disordered structure and, from the $r \Gamma$ value in Table 1, it would appear that it also leads to abnormally high repulsive interactions.

The remaining binuclear phthalocyanines have average $\theta$ values near two. If these molecules adsorbed on to the electrode surface in an "open" conformation then a $\theta$ value near two would not be expected since, as noted earlier, the $\pi-\pi$
TABLE 2. Half-bandwidths of the $Q$ band for CoTNPc and its binuclear derivatives as $\mathrm{Co}$ (III) and also as $\mathrm{Co}(\mathrm{I})^{a}$

\begin{tabular}{lcc}
\hline \hline \multirow{2}{*}{ Compound } & \multicolumn{2}{c}{ Half-bandwidths $\left(\mathrm{cm}^{-1}\right)$} \\
\cline { 2 - 3 } & Co(III) & Co(I) \\
\hline CoTNPc & 680 & 660 \\
C(2)[CoTrNPc $]_{2}$ & 765 & 735 \\
Cat(4)[CoTrNPc $]_{2}$ & 800 & 775 \\
EtMeO(5)[CoTrNPc $]_{2}$ & 785 & 775 \\
O(1)[CoTrNPc $]_{2}$ & 1000 & 920 \\
\hline
\end{tabular}

${ }^{a}$ These half-bandwidths were calculated from the spectra obtained by bulk electrolysis of DCB solutions containing these species along with an excess of tetrabutylammoniumhydroxide and $0.1 M$ TBAP $(80)$.

interactions which arise between the first and second layer of phthalocyanine molecules adsorbed on the electrode surface are too weak to stabilize a second layer. It would therefore appear that most of these binuclear species adsorb on to the electrode surface in some sort of cofacial arrangement. This configuration is easily obtained by $\mathrm{Cat}(4)[\mathrm{CoTrNPc}]_{2}$ and EtMeO(5)[CoTrNPc $]_{2}$, but the stacking of $\mathrm{C}(2)[\mathrm{CoTrNPc}]_{2}$ would necessitate that the phthalocyanine rings in the second layer lie above a surface bound ring of an adjacent $\mathrm{C}(2)[\mathrm{CoTrNPc}]_{2}$ molecule. The values of $r \Gamma$ reported for these binuclear compounds are fairly consistent and are quite similar to the value of -0.7 reported by Collman and Anson (28) for one of their cofacial cobalt porphyrins. It has been suggested that the source of repulsions observed for flatly adsorbed aromatic molecules such as these, is the parallel orientation of their dipoles (79).

Another interesting feature of these adsorption studies is illustrated in Fig. 4. The cyclic voltammograms for $\mathrm{O}(1)[\mathrm{CoTrNPc}]_{2}$ and $\mathrm{Cat}(4)[\mathrm{CoTrNPc}]_{2}$ display one adsorption wave for the $[\mathrm{Co}(\mathrm{II}) \mathrm{TrNPc}(-1)]^{+/} / \mathrm{Co}$ (II) $\operatorname{TrNPc}(-2)$ couple, just like that observed for the adsorption of CoTNPc on OPG (see Fig. 3). However, the cyclic voltammograms for $\mathrm{C}(2)[\mathrm{CoTrNPc}]_{2}$ and $\mathrm{EtMeO}(5)[\mathrm{CoTrNPc}]_{2}$ display two couples in the same potential region. Plots of $i_{\mathrm{p}}$ versus $\nu$ for the two couples are linear, thus both couples arise from adsorption processes. Frumkin isotherm analysis yielded values of $n$ close to unity which, when combined with the potential of these couples, suggests that these couples are both associated with the $[\mathrm{Co}(\mathrm{II}) \operatorname{TrNPc}(-1)]^{+} /$ $\mathrm{Co}(\mathrm{II}) \mathrm{TrNPc}(-2)$ process. The origin of these two adsorption processes may be explained in terms of the electronic coupling inherent in these binuclear compounds.

The theory of intramolecular coupling in these binuclear phthalocyanines has been presented elsewhere (66). In solution, these binuclear species are expected to exist in a dynamic equilibrium between various conformations, dependent upon the nature of the bridge since, in some cases, steric effects may provide barriers to free rotation. Therefore, the electronic absorption spectrum of a solution of one of these binuclear species would represent the summation of the spectra of a mixture of these conformers. The coupling in these species resulted in a blue-shifted $Q$ band which was also broadened, the degree of this broadening being a qualitative measure of the degree of electronic coupling in these binuclear species.

The half-bandwidths of the five phthalocyanine species investigated in this study are presented in Table $2(80)$. The relative extent of coupling in these compounds, as established 


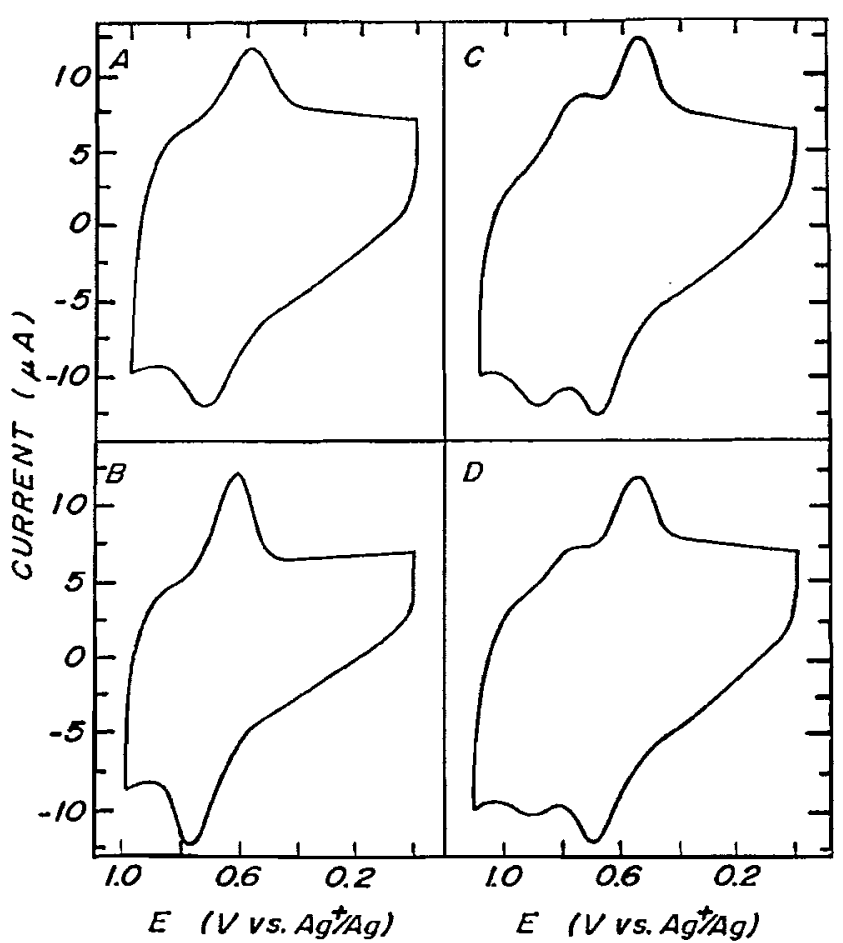

FIG. 4. Cyclic voltammograms displaying adsorption features of (a) $\mathrm{O}(1)\left[\mathrm{TNPcCo}_{2},(b) \mathrm{Cat}(4)[\mathrm{TNPcCo}]_{2},(c) \mathrm{C}(2)[\mathrm{TNPcCo}]_{2}\right.$, and (d) $\mathrm{EtMeO}(5)[\mathrm{TNPcCo}]_{2}$. All voltammograms were recorded at a scan rate of $100 \mathrm{mV} / \mathrm{s}$ for a binuclear concentration of ca. $5 \mu \mathrm{M}$ in $\mathrm{DCB}$ and $0.1 M$ TBAP. The waves shown here are associated with the $[\mathrm{Co}(\mathrm{II}) \mathrm{TNPc}(-1)]^{+} / \mathrm{Co}(\mathrm{II}) \mathrm{TNPc}(-2)$ couple.

by these half-bandwidths, is as follows:

[5] $\begin{aligned} \mathrm{O}(1)[\mathrm{CoTrNPc}]_{2} & >\mathrm{EtMeO}(5)[\mathrm{CoTrNPc}]_{2} \simeq \mathrm{Cat}(4)[\mathrm{CoTrNPc}]_{2} \\ & >\mathrm{C}(2)[\mathrm{CoTrNPc}]_{2}>\mathrm{CoTNPc}\end{aligned}$

Cyclic voltammograms of each of the binuclear species are presented in Fig. 4. In the voltammograms of $\mathrm{C}(2)[\mathrm{CoTrNPc}]_{2}$ and $\mathrm{EtMeO}(5)[\mathrm{Co} T r N P c]_{2}$, two adsorption waves are observed which arise from two distinct redox couples in close proximity. Similar voltammograms have been reported previously $(28,81)$ but, in these earlier reports, both of the redox processes could be observed when the species was in solution, not bound to the electrode surface. For each of the adsorbed binuclear species, one phthalocyanine ring lies on the electrode surface while the other ring is not in contact with it. The two redox couples, therefore, are regarded to arise from the bound Pc ring, and the bridged $P c$ ring which is not bound directly to the electrode. In solution, only one redox process is observed, common to both rings. In the more highly coupled species, namely $\mathrm{O}(1)[\mathrm{CoTrNPc}]_{2}$ and $\mathrm{Cat}(4)[\mathrm{CoTrNPc}]_{2}$, electron transfer across the bridge to the outer phthalocyanine ring is facile and therefore only one redox couple is observed. However, electron transfer across the saturated $\mathrm{C}(2)[\mathrm{CoTrNPc}]_{2}$ and $\mathrm{EtMeO}(5)[\mathrm{CoTrNPc}]_{2}$ bridges is inhibited and therefore the redox potential for the outer phthalocyanine ring could differ from that of the inner phthalocyanine ring. Although the $\mathrm{O}(1)[\mathrm{CoTrNPc}]_{2}$ bridge is, technically, also a saturated bridge, it is apparent from the half-bandwidth studies mentioned above, that electron transfer across this bridge is permissible. This proposal could explain the differences between the cyclic voltammograms given in Fig. 4, although further study would be necessary to establish the source of this behaviour conclusively.

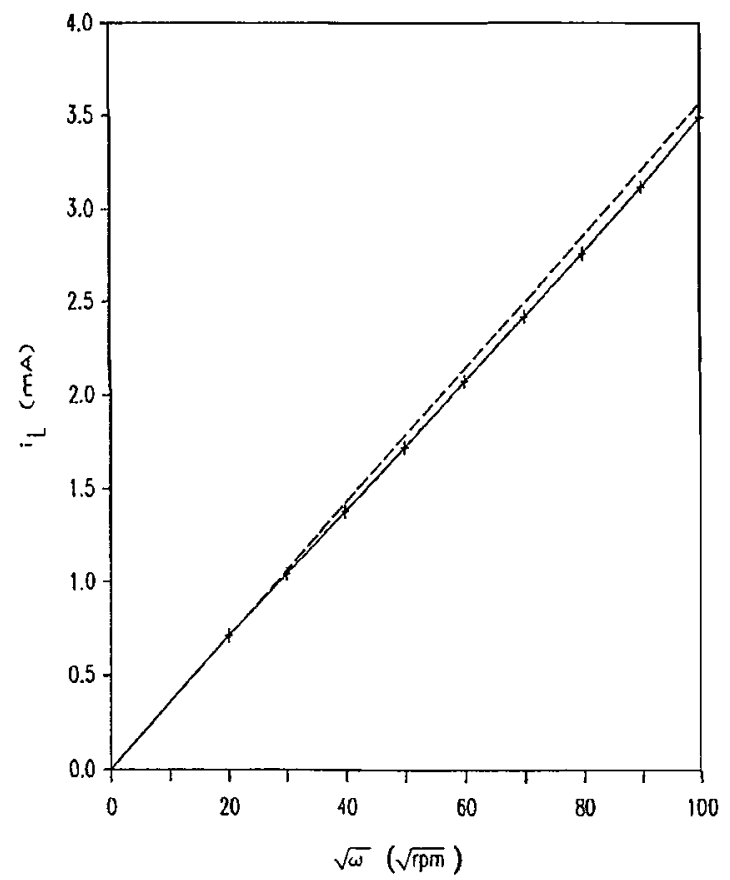

FIG. 5. Levich plot of the diffusion-limited $\mathrm{O}_{2}$ reduction current at a CoTNPc-modified OPG electrode. The dashed line is the response predicted by eq. [6] and the solid line is the fit through the experimental data denoted by + signs.

\section{(II) Oxygen studies}

The catalytic properties of these phthalocyanine species were investigated by means of rotating disc electrode (RDE) studies. The diffusion-limited current for such an experiment, expressed in $\mathrm{mA}$, is described by the expression (82)

$$
\text { [6] } \begin{aligned}
i_{\mathrm{L}}=1000 n A F C & \left(\frac{2 \pi v \omega}{60}\right)^{1 / 2} \\
& \times\left[\frac{0.62048 S^{-2 / 3}}{1+0.2980 S^{-1 / 3}+0.14514 S^{-2 / 3}}\right]
\end{aligned}
$$

where $v$ is the kinematic viscosity $\left(\mathrm{cm}^{2} / \mathrm{s}\right), \omega$ is the rotation rate (rpm), $S$ is the Schmidt number $(S=v / D), A$ is the electrode area $\left(\mathrm{cm}^{2}\right), F$ is Faraday's constant, and $C$ is the concentration of $\mathrm{O}_{2}\left(\mathrm{~mol} / \mathrm{cm}^{3}\right)$. A Levich plot $\left(i_{\mathrm{L}}\right.$ versus $\left.\omega^{1 / 2}\right)$ of the diffusion-limited $\mathrm{O}_{2}$ reduction current at a CoTNPc-modified OPG electrode is shown in Fig. 5. In the calculation of $i_{\mathrm{L}}$ for this Levich plot, the diffusion coefficient and concentration of $\mathrm{O}_{2}$ were taken as $1.67 \times 10^{-5} \mathrm{~cm}^{2} / \mathrm{s}(42)$ and $1.38 \times$ $10^{-6} \mathrm{~mol} / \mathrm{cm}^{3}(83)$, respectively, the kinematic viscosity was estimated at $9.97 \times 10^{-3} \mathrm{~cm}^{2} / \mathrm{s}(84)$, the Schmidt number was calculated to be 597 , and the value used for $n$ was two. The good agreement between the calculated diffusion-limited current and the experimentally observed limiting current suggests that $\mathrm{O}_{2}$ is undergoing a two-electron reduction to peroxide rather than a four-electron reduction to water. Further evidence for this two-electron reductive pathway will be presented later.

If an electrode process is hindered by a kinetic step, a plot of $i_{\mathrm{L}}$, or $i$, versus $\omega^{1 / 2}$ deviates from the linear relationship given in eq. [6] (71). The effect of this kinetic step on the current that flows in the potential region of mixed diffusion-kinetic control for a first-order process under steady-state conditions is given by the expression (85-88):

[7] $1 / i=1 / i_{\mathrm{k}}+1 / i_{\mathrm{L}}$ 
TABLE 3. Average values of $n$ for the electrocatalytic reduction of oxygen in $0.10 \mathrm{MNaOH}$ at an OPG electrode modified with CoTNPc or one of its binuclear derivatives

\begin{tabular}{|c|c|c|c|c|}
\hline \multirow[b]{3}{*}{ Compound } & \multicolumn{4}{|c|}{$n$} \\
\hline & \multicolumn{4}{|c|}{ Potential (V versus sce) } \\
\hline & -0.450 & -0.500 & -0.550 & -0.600 \\
\hline CoTNPc & $1.94 \pm 0.17$ & $1.93 \pm 0.11$ & $1.91 \pm 0.10$ & $1.93 \pm 0.06$ \\
\hline $\mathrm{O}(1)[\mathrm{CoTrNPc}]_{2}$ & $2.07 \pm 0.02$ & $2.04 \pm 0.02$ & $2.02 \pm 0.02$ & $2.01 \pm 0.01$ \\
\hline $\mathrm{C}(2)[\mathrm{CoTrNPc}]_{2}$ & $2.09 \pm 0.01$ & $2.05 \pm 0.01$ & $2.01 \pm 0.01$ & $1.99 \pm 0.02$ \\
\hline $\mathrm{Cat}(4)[\mathrm{CoTrNPc}]_{2}$ & $2.10 \pm 0.09$ & $2.03 \pm 0.01$ & $1.99 \pm 0.01$ & $1.98 \pm 0.02$ \\
\hline $\mathrm{EtMeO}(5)[\mathrm{CoTrNPc}]_{2}$ & $1.94 \pm 0.01$ & $1.94 \pm 0.02$ & $1.94 \pm 0.01$ & $1.96 \pm 0.01$ \\
\hline
\end{tabular}

TABLE 4. Kinetic currents, in $\mathrm{mA}$, and normalized kinetic currents (in parentheses) for oxygen reduction in $0.10 \mathrm{M} \mathrm{NaOH}$ at OPG electrodes modified with CoTNPc or one of its binuclear derivatives (electrode area $=0.493 \mathrm{~cm}^{2}$ )

\begin{tabular}{|c|c|c|c|c|c|}
\hline \multirow[b]{2}{*}{ Compound } & \multicolumn{4}{|c|}{ Potential (V versus sce) } & \multirow{2}{*}{$\begin{array}{c}\text { Average } \\
\text { normalized } \\
i_{k}\end{array}$} \\
\hline & -0.450 & -0.500 & -0.550 & -0.600 & \\
\hline CoTNPc & $\begin{array}{l}1.51 \\
(1)\end{array}$ & $\begin{array}{l}3.00 \\
(1)\end{array}$ & $\begin{array}{l}5.58 \\
(1)\end{array}$ & $\begin{array}{l}9.95 \\
(1)\end{array}$ & 一 \\
\hline $\mathrm{C}(2)[\mathrm{CoTrNPc}]_{2}$ & $\begin{array}{c}1.64 \\
(1.09)\end{array}$ & $\begin{array}{c}3.20 \\
(1.07)\end{array}$ & $\begin{array}{c}5.90 \\
(1.06)\end{array}$ & $\begin{array}{l}11.01 \\
(1.11)\end{array}$ & $1.08 \pm 0.02$ \\
\hline $\operatorname{Cat}(4)\left[\mathrm{Co} \mathrm{TrNPc}_{2}\right.$ & $\begin{array}{c}1.84 \\
(1.22)\end{array}$ & $\begin{array}{c}3.91 \\
(1.30)\end{array}$ & $\begin{array}{c}7.95 \\
(1.42)\end{array}$ & $\begin{array}{l}16.01 \\
(1.61)\end{array}$ & $1.39 \pm 0.17$ \\
\hline $\mathrm{EtMeO}(5)[\mathrm{Co} \operatorname{TrNPc}]_{2}$ & $\begin{array}{c}2.35 \\
(1.56)\end{array}$ & $\begin{array}{c}4.38 \\
(1.46)\end{array}$ & $\begin{array}{c}7.68 \\
(1.38)\end{array}$ & $\begin{array}{l}13.08 \\
(1.31)\end{array}$ & $1.43 \pm 0.10$ \\
\hline $\mathrm{O}(1)[\mathrm{CoTrNPc}]_{2}$ & $\begin{array}{c}2.45 \\
(1.62)\end{array}$ & $\begin{array}{c}4.61 \\
(1.54)\end{array}$ & $\begin{array}{c}8.15 \\
(1.46)\end{array}$ & $\begin{array}{l}13.89 \\
(1.40)\end{array}$ & $1.50 \pm 0.10$ \\
\hline
\end{tabular}

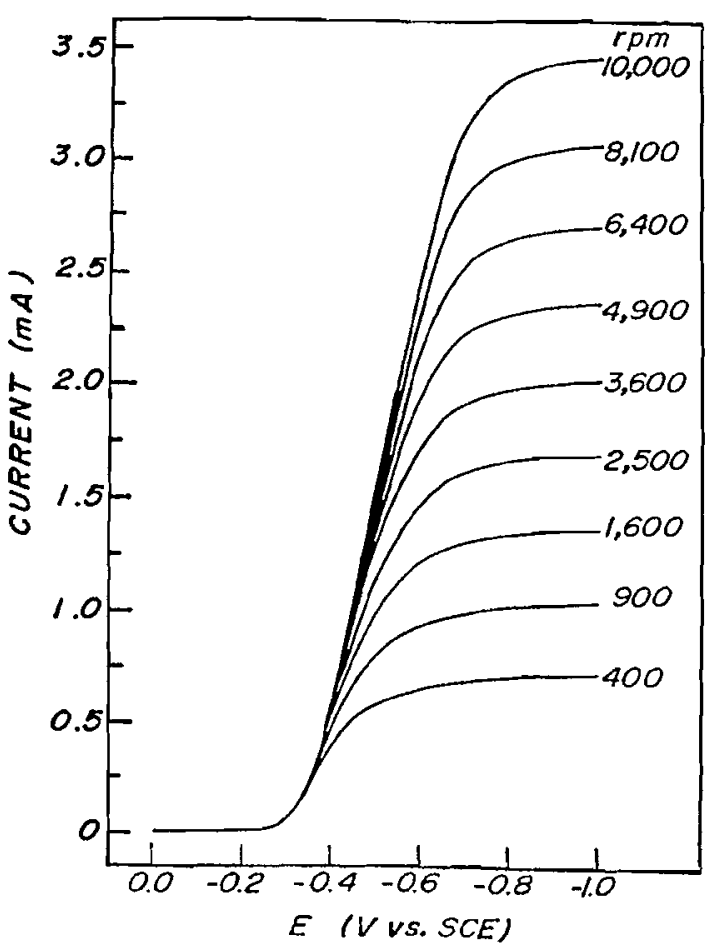

FIG. 6. Reduction of molecular oxygen at a rotating OPG electrode modified CoTNPc in an $\mathrm{O}_{2}$-saturated $0.10 \mathrm{M} \mathrm{NaOH}$ solution. in which $i_{\mathrm{k}}$ is the kinetically-limited current. A plot of $1 / i$ versus $1 / \omega^{1 / 2}$, known as the Koutecky-Levich plot, establishes this kinetically-limited current which is equivalent to the current that would flow if the concentration of $\mathrm{O}_{2}$ at the electrode surface could be maintained at its bulk concentration during the reduction process. Therefore, $i_{\mathrm{k}}$ at a given potential is directly proportional to the maximum rate at which $\mathrm{O}_{2}$ can be reduced to peroxide at the catalyst-modified electrode at that potential (89).

The reduction of $\mathrm{O}_{2}$ at an OPG electrode modified with CoTNPc is shown in Fig. 6. These scans were recorded at $10 \mathrm{mV} / \mathrm{s}$, but may be considered to be steady-state curves since no hysteresis was observed between the forward and reverse scans. Following the procedures presented by Frumkin and Tedoradse (90), Koutecky-Levich plots at $-0.450 \mathrm{~V}$, $-0.500 \mathrm{~V},-0.550 \mathrm{~V}$, and $-0.600 \mathrm{~V}$ were constructed. Koutecky-Levich plots of $\mathrm{O}_{2}$ reduction at $-0.450 \mathrm{~V}$ for OPG electrodes modified with CoTNPc and each of its binuclear derivatives are given in Fig. 7. The scatter for KouteckyLevich plots was small $(R>0.999)$ and the $n$ values calculated from the slopes of these plots (Table 3 ) were consistent with a two-electron process yielding peroxide as the reduction product. The different intercepts for the Koutecky-Levich plots illustrate that the catalytic activity of these species differ. The kinetically-limited currents for oxygen reduction are presented in Table 4. These kinetically-limited currents have been normalized to the CoTNPc data to rank the catalytic efficiency of the binuclear species and these normalized kineticallylimited currents are presented in parentheses in Table 4. 


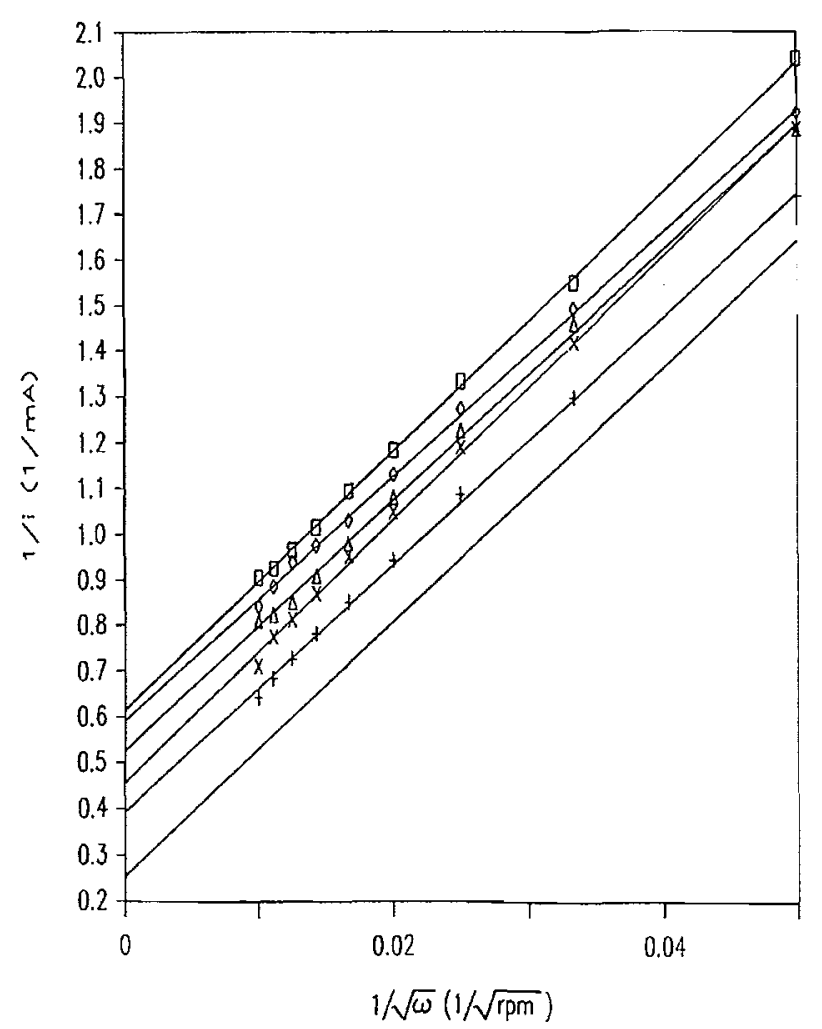

Fig. 7. Koutecky-Levich plots for the reduction of molecular oxygen in $0.10 \mathrm{M} \mathrm{NaOH}$ at $-0.450 \mathrm{~V}$ versus sce on OPG electrodes madified with $\square$, CoTNPc;,$+ \mathrm{O}(1)[\mathrm{CoTrNPc}]_{2} ; \diamond, \mathrm{C}(2)[\mathrm{Co} T r N P c]_{2}$; $\triangle, \mathrm{Cat}(4)[\mathrm{CoTrNPc}]_{2} ;$ or $\times, \mathrm{EtMeO}(5)[\mathrm{CoTrNPc}]_{2}$. A theoretical two-electron line is shown at the bottom of the graph for comparison.

The standard deviation for the average normalized kineticallylimited currents is less than $15 \%$ which though somewhat large, is similar to the deviation reported in another study (91). These normalized currents indicate the reactivities of these species towards oxygen reduction are as follows:

[8] $\mathrm{O}(1)[\mathrm{CoTrNPc}]_{2}>\mathrm{EtMeO}(5)[\mathrm{CoTrNPc}]_{2} \approx \mathrm{Cat}(4)[\mathrm{CoTrNPc}]_{2}$

$$
>\mathrm{C}(2)[\mathrm{CoTrNPc}]_{2}>\mathrm{CoTNPc}
$$

It is surely significant that this ranking is the same as given for the electronic coupling of these species.

Although the binuclear CoTNPc compounds have shown increased activity towards the electrocatalytic reduction of molecular oxygen, the potential at which this process occurs in $\mathrm{pH} 13 \mathrm{NaOH}$ solution is approximately the same as that for CoTSPc under the same conditions (41), and rather too negative to be practical for a fuel cell catalyst. Present studies are being directed towards the shifting of the molecular oxygen reduction potential to more positive values by performing these experiments under acidic conditions, and also to devise conditions under which the direct four-electron reduction process will be favoured.

\section{Summary}

In basic media, binuclear cobalt phthalocyanines were shown to be more active towards the electrocatalytic reduction of molecular oxygen than the corresponding mononuclear species. The increased activity of these binuclear compounds has been attributed to the increased electronic coupling between the phthalocyanine rings of these species. Current studies include
CoPc species showing a much greater degree of intramolecular coupling than observed here (92). A mechanistic study of CoTNPc over the $\mathrm{pH}$ range 1 to 13 will also be reported shortly.

\section{Acknowledgements}

Gratitude is extended to the Natural Sciences and Engineering Research Council of Canada for financial support in the forms of an operating grant and a postgraduate scholarship (M.R.H.). Support from the Office of Naval Research (Washington) is also appreciated. The authors also wish to express their gratitude to Dr. Pavel Janda for beneficial discussions.

1. T. Kuwana, M. Fujihira, K. Sunakawa, and T. Osa. J. Electroanal. Chem. 88, 299 (1978).

2. A. Bettelleim and T. Kuwana. Anal. Chem. 51, 2257 (1979).

3. A. Bettel.heim, R. J. H. Chan, and T. KuWANa. J. Electroanal. Chem. 99, 391 (1979).

4. N. Kobayashl, T. Matsue, M. Fujlhira, and T. Osa. J. Electroanal. Chem. 103, 427 (1979).

5. M. R. Tarasevich and K. A. Radyushikina. Russ. Chem. Rev. Engl. Transl. 49, 1498 (1980).

6. J. A. R. van Veen, J. F. van BaAR, C. J. Kroese, J. G. F. Coolegem, N. DE WIT, and H. A. Colijn. Ber. Bunsenges. Phys. Chem. 85, 693 (1981).

7. J. A. R. van Veen and H. A. Colijn. Ber. Bunsenges. Phys. Chem. 85, 700 (1981).

8. P. A. Forshey, T. Kuwana, N. Kobayashi, and T. Osa. Adv. Chem. Ser. 201, 601 (1982).

9. N. Kobayashi, M. Fujlhira, T. Osa, and S. Dong. Chem. Lett. 575 (1982).

10. A. Bettelmeim, R. Parash, and D. Ozer. J. Electrochem. Soc. 129,2247 (1982)

11. N. Kobayashi and T. Osa. J. Electroanal. Chem: 157, 269 (1983).

12. A. Bettelheim, D. Ozer, and R. Parash. J. Chem. Soc. Faraday Trans. 1, 79, 1555 (1983).

13. P. A. ForsheY and T. Kuwana. Inorg. Chem. 22, 699 (1983)

14. K. OKabayashi, O. IKeda, and H. Tamura. J. Chem. Soc. Chem. Commun. 684 (1983).

15. O. Ikeda, K. OKabayashi, and H. Tamura. Chem. Lett. 1821 (1983).

16. O. Ikeda, H. Fukuda, and H. Tamura. J. Chem. Soc. Chem. Commun. 567 (1984).

17. D. Ozer, R. Parash, F. Broitman, U. Mor, and A. BettelHEIM. J. Chem. Soc. Faraday Trans. 1, 80, 1139 (1984).

18. O. IKEDA, H. FUKedA, T. KoJima, and H. Tamura. J. Electrochem. Soc, 132, 3069 (1985).

19. C.-L. Ni and F. C. ANson. Inorg. Chem. 24, 4754 (1985).

20. F. Bedioul, C. Bongars, C. Hinnen, C. Bied-Charreton, and J. Devynck. Bull. Chim. Soc. Fr. 679 (1985).

21. O. IKeda, K. OKabayashi, N. Yoshida, and H. Tamura. J. Electroanal, Chem. 191, 157 (1985).

22. J. P. Collman, M. Marocco, P. Denisevich, C. Koval, and F. C. Anson. J. Electroanal. Chem. 101, 117 (1979).

23. J. P. Collman, P. Denisevich, Y. Konal, M. Marocco, C. Koval, and F. C. Anson. J. Am. Chem. Soc. 102, 6027 (1980).

24. R. R. Durand, JR., J. P. Collman, and F. C. Anson. J. Electroanal. Chem. 151, 289 (1983).

25. J. P. Collman, F. C. Anson, C. E. Barnes, C. S. Bencosme, T. Geiger, E. R. Evitt, R. P. Kreh, K. Meier, and R. B. Pettman. J. Am. Chem. Soc. 105, 2694 (1983).

26. J. P. Collman, C. S. Bencosme, R. R. Durand, JR., R. P. Kreh, and F. C. Anson. J. Am. Chem. Soc. 105, 2699 (1983).

27. J. P. Collman, F. C. Anson, C. E. Barnes, and B. D. Miller. J. Am. Chem. Soc. 105, 2704 (1983).

28. R. R. Durand, Ir., C. S. Bencosme, J. P. Collman, and F. C. ANSON. J. Am. Chem. Soc. 105, 2710 (1983).

29. C. K. Chang. J. Chem. Soc. Chem. Commun. 800 (1979). 
30. C. K. Chang. Biochem. Clin. Aspects Oxygen, 437 (1978).

31. C. K. Chang. Adv. Chem. Ser. 173, 162 (1979).

32. H. Y. Liu, M. J. Weaver, C.-B. Wang, and C. K. Chang. J. Electroanal. Chem. 145, 439 (1983).

33. C. K. Chang and I. Abdalmuhdr. Angew. Chem. Int. Ed. Engl. 23, 164 (1984)

34. C. K. Chang, H. Y. Liu, and I. Abdalmuhdi. J. Am. Chem. Soc. 106, 2725 (1984).

35. H.-Y. Liu, I. Agdalmuhdi, C. K. Chang, and F. C. Anson. J. Phys. Chem. 89, 665 (1985).

36. R. JASINSKI. J. Electrochem. Soc. 112, 526 (1965).

37. A. Kozawa, V. E. Zilionis, and R. J. Brodd. J. Electrochem. Soc. 117, $1470(1970)$.

38. A. KozAWA, V. E. Zilionis, and R. J. Brodd. J. Electrochem. Soc. 117, 1474 (1970).

39. A. Kozawa, V. E. Zilionis, and R. J. Brodd. J. Electrochem. Soc. 118, 1705 (1971).

40. J.-P. RANDIN. Electrochim. Acta, 19, 83 (1974).

41. J. ZaGal, R. K. Sen, and E. Yeager. J. Electroanal. Chem. 83, 207 (1977).

42. J. ZaGal, P. Bindra, and E. Yeager. J. Electrochem. Soc. 127, $1506(1980)$.

43. F. VAN DEN Brink, W. Visscher, and E. Barendrecht. J. Electroanal, Chem. 157, 283 (1983).

44. F. VAN DEN BRINK, W. VISSCHER, and E. BARENDRECHT. J. Electroanal. Chem. 157, 305 (1983).

45. F. VAN DEN BRINK, W. VISSCHER, and E. BARENDRECHT. J. Electroanal. Chem. 172, 301 (1984).

46. F. VAN DEN BRINK, W. VISSCHER, and E. BARENDRECHT. J. Electroanal. Chem. 175, 279 (1984).

47. J. H. Zagal, M. Paez, J. Sturm, and S. Ureta-Zanartu. J. Electroanal. Chem. 181, 295 (1984).

48. T. Osaka, K. NaOI, T. Hirabayashi, and S. Nakamura. Bull. Chem. Soc. Jpn. 59, 2717 (1986).

49. A. Elzing, A. yan der Putten, W. Visscher, and E. BARENDRECHT. J. Electroanal. Chem. 200, 313 (1986).

50. A. van der Putten, A. Elzing, W. Visscher, and E. BARENDRECHT. J. Electroanal. Chem. 214, 523 (1986).

51. D. WOHRLE. Fortschr. Hochpolym. Forsch. 10, 35 (1972).

52. M. SAVY, P. ANDro, C. Bernard, and G. Magner. Electrochim. Acta, 18, 191 (1973).

53. M. SAVY, P. ANDro, and C. Bernard. Electrochim. Acta, 19, $403(1974)$

54. A. J. ApPleby and M. Savy. Natl. Bur. Stand. (U.S.), Spec. Publ. 455, 241 (1976).

55. A. J. Appleby, J. Fleisch, and M. SAvy. J. Catal. 44, 281 (1976).

56. S. Maroie, M. SAYY, and J. J. Verbist. Inorg. Chem. 18, 2560 (1979).

57. L. Kreja and A. Plewka. Electrochim. Acta, 25, 1283 (1980).

58. H. Behret, H. Binder, G. Sandstede, and G. G. Scherer. J. Electroanal. Chem. 117, 29 (1981).

59. J. Blomeuist, U. Helgeson, and L. C. Moberg. Electrochim. Acta, 27, 1445 (1982).

60. J. Blomeuist, U. Helgeson, and L. C. Moberg. Electrochim. Acta, 27, 1453 (1982).

61. L. KReJa. Electrochim. Acta, 28, 1807 (1983).

62. T. HIRAI and J.-I. YAMaKI. J. Electrochem. Soc. 132, 2125 (1986).
63. C. C. Leznoff, S. Greenberg, S. M. Marcuccio, P. C Minor, P. Seymour, and A. B. P. Lever. Inorg. Chim. Acta, 89, L35 (1984).

64. C. C. Leznoff, S. M. Marcuccio, S. Greenberg, A. B. P. LeVER, and K. B. Tomer. Can. J. Chem. 63, 623 (1985).

65. S. M. Marcuccio, P. I. Svirskaya, S. GreenberG, A. B. P. Lever, and C. C. Leznoff. Can. J. Chem. 63, 3057 (1985).

66. E. S. Dodsworth, A. B. P. Lever, P. Seymour, and C. C. LEZnOFF. J. Phys. Chem. 89, 5698 (1985).

67. W. A. Nevin, W. LiU, and A. B. P. Lever. Can. J. Chem. 65 , 855 (1987).

68. M. Gouterman. The porphyrins. Vol. III. Edited by D. Dolphin. Pt. A, Academic Press, New York. 1978. p. 1.

69. S. Greenberg, S. M. Marcuccio, C. C. Leznoff, and K. B. TOMER. Synthesis, 406 (1986)

70. M. R. Hempstead. Ph.D. Thesis, York University. 1987.

71. A. J. BARD and L. R. FAULKNER. Electrochemical methods. John Wiley and Sons, New York. 1980.

72. R. H. Worschall and I. Shain. Anal. Chem. 39, 1514 (1967).

73. W. A. Nevin, M. R. Hempstead, W. Liu, C. C. Leznoff, and A. B. P. Lever. Inorg. Chem. 26, 570 (1987).

74. J. H. ZAGaL. Ph.D. Thesis, Case Western Reserve University. 1978.

75. A. N. Frumkin. Z. Phys, 35, 792 (1926).

76. E. LAviron. J. Electroanal. Chem. 52, 395 (1974).

77. J. Schreurs and E. Barendrecht. Recl. Trav. Chim. Pays-Bas, 103, 205 (1984).

78. P. Nikitas. J. Chem. Soc., Faraday Trans. 1, 81, 1767 (1985).

79. A. N. Frumkin and B. B. Damaskin. Pure Appl. Chem. 15, 263 (1967).

80. A. B. P. Lever, M. R. Hempstead, C. C. Leznoff, W. LiU, M. Melnik, W. A. Nevin, and P. Seymour. Pure Appl. Chem. 58, 1467 (1986).

81. A. P. Brown, C. Koval, and F. C. Anson. J. Electroanal Chem. 72, 379 (1976).

82. J. Newman. J. Phys. Chem. 70, 1327 (1966)

83. W. F. LINKE. Solubilities of inorganic and metal organic compounds. Vol. II. 4th ed. Am. Chem. Soc. Washington, D.C., 1965. p. 1219.

84. R. C. WEAST (Editor). Handbook of chemistry and physics. 57th ed., CRC Press, Cleveland, OH. 1977.

85. J. KouteCKY and V. G. LeVICH. Zh. Fiz. Khim. 32, 1565 (1957)

86. Yu. V. Pleskov and V. Yu. FILINOVSKI (Editors). Studies in Soviet science: the rotating disc electrode. Consultants Bureau, New York. 1976. p. 90

87. P. N. Ross and P. C. Andricacos. J. Electroanal. Chem. 154, 205 (1983)

88. F. Opekar and P. Beran. J. Electroanal. Chem. 69, 1 (1976).

89. K. Shigemara and F. C. Anson. J. Phys. Chem. 86, 2776 (1982).

90. A. Frumkin and G. Tedoradse. Z. Elektrochem. 62, 251 (1958).

91. T. E. Mallouk, V. Cammarata, J. A. Crayson, and M. S. Wrighton. J. Phys. Chem. 90, 2150 (1986).

92. C. C. Leznoff, H. Lam, S. M. Marcuccio, W. A. Nevin, P. Janda, N. Kobayashi, and A. B. P. Lever. J. Chem. Soc. Chem. Commun. 699 (1987). 


\section{MONOLAYER CHARACTERISTICS OF SOME MULTINUCLEATE PHTHALOCYANINES*}

J.-H. KIM, T. M. COTTON AND R. A. UPHAUS

Department of Chemistry, University of Nebraska, Lincoln, NE 68588-0304 (U.S.A.)

C. C. LEZNOFF

Department of Chemistry, York University, Downsview, Ontario M3J IP3 (Canada)

(Received July 27, 1987; accepted August 23, 1987)

Surface pressure-area isotherms were established for a series of seven derivatized phthalocyanine compounds containing from one to four covalently linked macrocycles. Good solubility in spreading solvents was conferred by the presence of four neopentoxyl groups per macrocycle. All compounds studied formed strong, stable monolayers with high breaking pressures (about $50 \mathrm{mN} \mathrm{m}^{-1}$ or greater). Observed surface pressure-area isotherms were of the most simple kind, with no indication of phase transitions or discontinuities, with one exception. Minimal molecular areas were seen at lowest compression rates and higher temperatures, indicating that these systems have a large number of configurational states which are not capable of restructuring quickly into a compact monolayer of highest density. For some compounds it appears that orientation on the water surface can be essentially flat. Most previously studied phthalocyanine monolayers suggest that the macrocycles tend always to orient edge-on at some acute angle to the water surface because of the very strong cofacial energies of interaction. With other compounds of this group, it is evident that the macrocycles can assume orientations either parallel or perpendicular to the surface, others having intermediate orientations as well. In addition, one multinucleate compound probably assumes a bilayer structure at high surface pressures. The range of orientations available in these systems should appreciably extend the utility of phthalocyanines in monolayers transferred by the Langmuir-Blodgett technique. The present study indicates that a more complete exploitation of the possibilities of organic synthesis can result in a more varied monolayer behavior than seen hitherto.

\section{INTRODUCTION}

The unique optical and electrical properties of phthalocyanine (Pc), as well as its remarkable chemical stability, have stimulated many monolayer studies having the ultimate objective of incorporating monolayers of $\mathrm{Pc}$ as the functional element

* Paper presented at the Third International Conference on Langmuir-Blodgett Films, Göttingen, F.R.G., July 26-31, 1987. 
in various sensors or other devices. The parent, underivatized molecule is intractable and insoluble in all common solvents. Derivatized species must therefore be used for monolayer formation, while maintaining as completely as possible the intrinsic character of the parent compound. Thus, the tetra-t-butyl derivative has been extensively studied ${ }^{1}$. However, even in this compound the strong cofacial bonding interactions may not allow disaggregation to the point where individual molecules can be said to be present in the traditional context of spread monolayers.

Kuhn, Möbius and coworkers ${ }^{2}$ were the first to demonstrate the great potential afforded by the modulation of specific monolayer properties through subtle modification of molecular architecture. This fruitful mode of attack is just beginning to be applied to Pc structures intended for monolayer formation ( $c f$. ref. 3 and citations therein). The recent preparation of novel Pc systems by Leznoff et al. ${ }^{4}$ provides an interesting new group of Pc compounds having possible application to monolayer constructions. They consist of single or multiple macrocycles connected by bridging chains of various lengths (Fig. 1). The neopentoxyl substituent groups provide high solubility in common spreading solvents such as chloroform. The variation in the linking of macrocycles provides the possibility for a great range of assumable configurational states in spread monolayers.

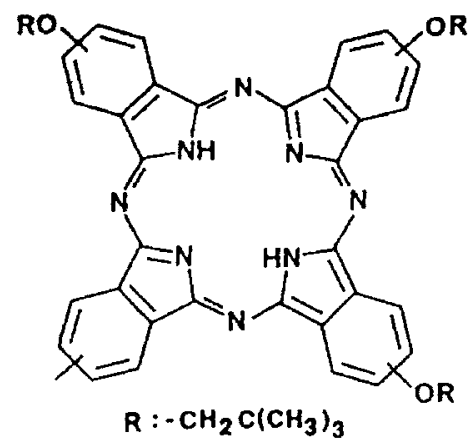

Fig. 1. Pc structures.

\begin{tabular}{ll}
\hline Designation & Structure \\
\hline SG-A & $\mathrm{Pc}-\mathrm{OR}$ \\
SG-B & $\mathrm{Pc}-\mathrm{Pc}$ \\
SG-25 & $\mathrm{Pc}-\mathrm{O}-\mathrm{Pc}$ \\
SG-35 & $\mathrm{Pc}-\mathrm{CH}-\mathrm{CH}_{2}-\mathrm{Pc}$ \\
SG-C & $\mathrm{Pc}-\mathrm{O}-\mathrm{CH}_{2} / \mathrm{CH}_{3}$ \\
& \\
& $\mathrm{Pc}-\mathrm{O}-\mathrm{CH}_{2}-\mathrm{CH}_{2} \mathrm{CH}_{3}$ \\
SG-26R & $\mathrm{Pc}-\mathrm{O}-\mathrm{Pc}-\mathrm{O}-\mathrm{Pc}_{2}$ \\
SG-tet & $\mathrm{Pc}-\mathrm{O}-\mathrm{CH}_{2} \backslash \mathrm{CH}-\mathrm{O}-\mathrm{Pc}$ \\
& $\mathrm{Pc}-\mathrm{O}-\mathrm{CH}_{2} \mathrm{CH}_{2}-\mathrm{O}-\mathrm{Pc}$ \\
\hline
\end{tabular}


Apparent molecular areas as determined from surface isotherms are not sufficient evidence for the existence of a specific orientational state, for which other techniques must be used. However, the suggested orientations for the present systems are consistent with the apparent determined areas.

\section{EXPERIMENTAL DETAILS}

The preparation of all compounds was as described in the literature ${ }^{4}$. Chloroform was used as the spreading solvent after purification in an alumina column and addition of $1 \%$ ethanol.

Surface isotherms were determined with a Wilhelmy filter paper sensor and a thermostated, automated Teflon Langmuir trough. Area and surface tension data were digitized and stored in a dedicated computer. All measurements were made on systems spread on water of near-neutral $\mathrm{pH}$ which was previously subjected to deionization, reverse osmosis treatment and final distillation in an all glass system.

\section{RESULTS AND DISCUSSION}

All the compounds of this series formed strong monolayers with collapse pressures of about $50 \mathrm{mN} \mathrm{m} \mathrm{m}^{-1}$ or greater. Isotherms were highly reproducible to within several per cent, were of simple character and, with one exception, lacked plateaux or indications of phase transitions. The apparent areas per molecule as determined from the surface isotherms are summarized in Table I. The salient features of the isotherms of the individual compounds are summarized as follows.

TABLE I

MOLECULAR AREAS OF MULTINUCLEATE PHTHALOCYANINES

\begin{tabular}{llll}
\hline Compound & $\begin{array}{l}\text { Area per } \\
\text { molecule }\left(\AA^{2}\right)\end{array}$ & $\begin{array}{l}\text { Temperature } \\
\left({ }^{\circ} \mathrm{C}\right)\end{array}$ & $\begin{array}{l}\text { Compression rate } \\
\left(\AA^{2} \mathrm{~mol}^{-1} \mathrm{~min}^{-1}\right)\end{array}$ \\
\hline SG-A & 100 & 22 & 30 \\
SG-B & 80 & 22 & 10 \\
& 155 & 22 & 85 \\
SG-C & 125 & 22 & 20 \\
& 288 & 13 & 100 \\
SG-25 & 246 & 22 & 100 \\
SG-26R & 242 & 32 & 100 \\
SG-35 & 105 & 22 & 55 \\
SG-tet & 338 & 22 & 85 \\
& 60 & 22 & 30 \\
& 192 & 22 & 50 \\
\hline
\end{tabular}

\section{1. $S G-A$}

The apparent molecular area of this compound was found to vary somewhat as a function of the compression rate, the lowest compression rate producing a value of $80 \AA^{2}$. This indicates that the structuring of individual molecules into the most dense 
packing cannot occur at high rates of compression. At the maximum packing density the neopentoxyl groups must be forced out of the plane of the monolayer and can make no contribution to the value of the apparent molecular area. From the dimensions of the parent Pc based on X-ray studies ${ }^{5}$, the molecule can be approximated as a square of about $10 \AA$ on a side. However, from two-dimensional models which more closely approximate the real contours of the molecule, it is seen that the densest packing of molecular shapes yields a minimum area of about $76 \AA^{2}$, close to the observed value of $80 \AA^{2}$, assuming no contribution from the side chains. The only other reported instance ${ }^{6}$ of a Pc macrocycle oriented parallel to the water surface in its spread monolayer is that of the copper octa(dodecoxymethyl) Pc.

Mixed monolayers of SG-A and methyl eicosanoate were prepared at various mole ratios, and isotherms determined. The isotherms indicated that the two compounds were miscible. Observed values for mixed monolayer areas were less than those calculated on the basis of molecular areas of the pure components and their mole ratios at various concentrations. The mixed monolayer systems were evidently true molecular dispersions rather that separate, discrete mosaic patches of pure constituents.

The surface isotherms determined for SG-A is shown in Fig. 2 and is typical of those seen for all other compounds studied, with the exception of SG-C.

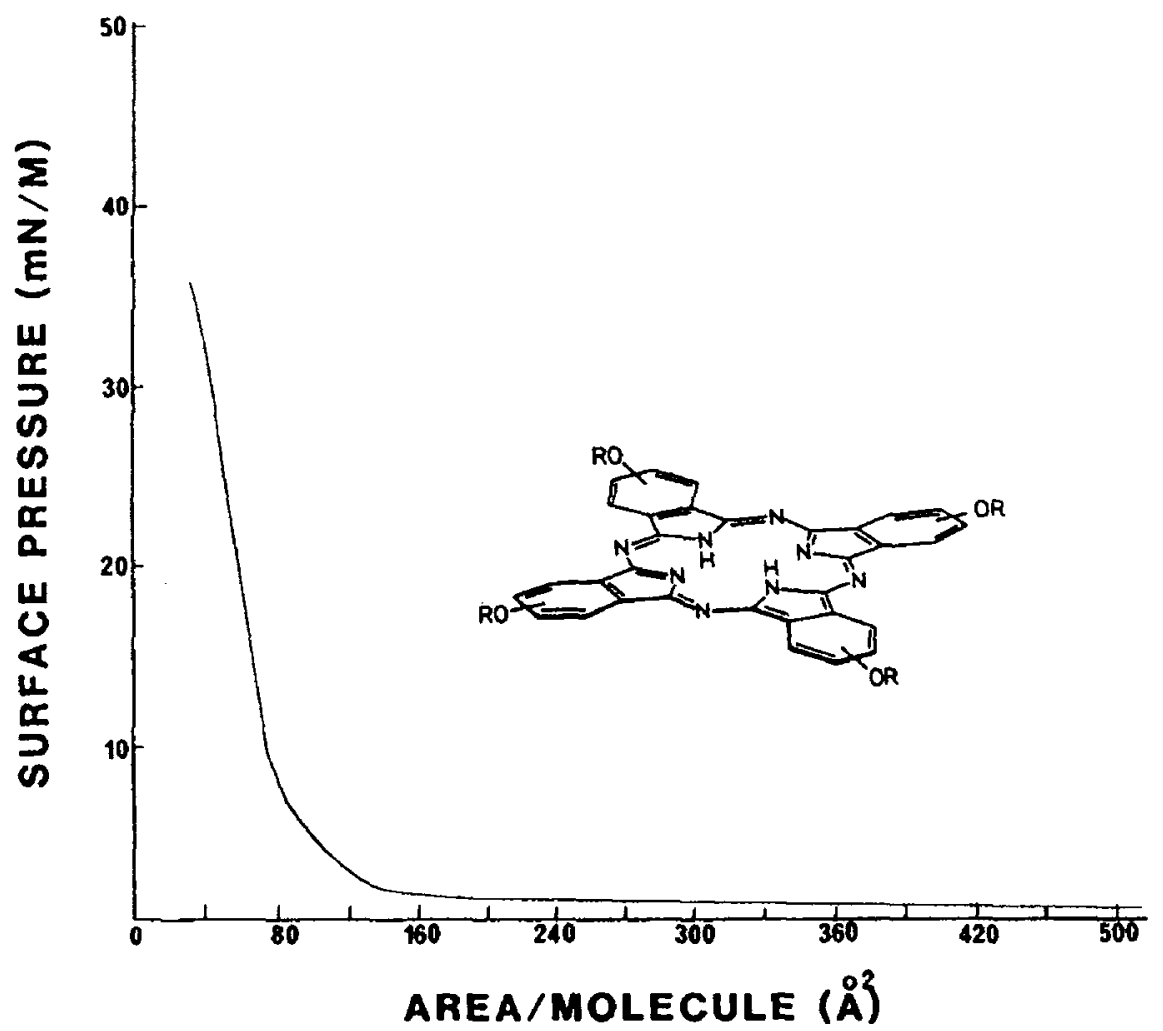

Fig. 2. Surface pressure-area isotherms of SG-A. 


\section{2. $S G-B, S G-25, S G-35$ and $S G-C$}

All these compounds have two Pc macrocycles linked together by a variety of interconnecting bridges. The allowable number of configurational states varies greatly throughout the series and this is reflected in the observed molecular areas. An assessment of the influence of small variation in molecular structure on the nature of the resulting spread monolayer is thus possible.

These dimeric forms could be of value as surrogates for the chlorophyll "special pair" found in the photosynthetic reaction center. There, light energy is converted into chemical potential after a rapid charge separation. The chlorophyll special pair in vivo is held at a specific orientation and intermolecular distance by interaction with the protein matrix, and the complete structure of the complex is now known?

Pc systems have been extensively studied in the context of their electrocatalytic, photovoltaic and photocatalytic effects. For the case of simple $\mathrm{Fe}^{\mathrm{II}} \mathrm{Pc}$, it is known that the four-electron reduction of oxygen can be effected. Binuclear species are expected to be more efficient.

\section{3. $S G-B$}

The direct bonding of the rings of SG-B must produce a steric hindrance great enough to prevent the flexibility necessary for coplanar structuring of both macrocycles. However, this direct link also is too short to allow cofacial orientation. The decrease in molecular area at decreased compression rates indicates that a monolayer of most dense packing will not be quickly structured at higher compression rates. The values determined for the apparent area per molecule could be reasonably interpreted as indicating that the system has one macrocycle flat on the water surface with the second ring assuming some oblique angle.

\section{4. $S G-25$}

The intermacrocycle connection in SG-25 affords a much greater flexibility than seen in SG-B, and the possibility that macrocycles would tend to orient cofacially, with the oxygen tending to interact with the water surface. The small molecular area could be interpreted as an indication of edge-on orientation of less than $90^{\circ}$ to the water plane. Alternatively, one macrocycle could be flat on the surface with the second ring forming a bilayer on top of it.

\section{5. $S G-35$}

In this case, no oxygen is present to confer hydrophilicity and the Pc macrocycles are separated at distances even greater than those in SG-25. The possibility for cofacial interaction of the rings is greater, and for this reason the SG-35 monolayer may more closely resemble that of tetra-t-butyl Pc. It appears that the average angle of macrocycle planes to the surface must be near $90^{\circ}$ in order to produce the observed molecular area of only $60 \AA^{2}$, which is twice $10 \AA$ (the Pc edge distance) multiplied by $3 \AA$ (the thickness of the macrocycle).

\section{6. $S G-C$}

Of all the compounds studied, only SG-C produced isotherms which invariably had shoulders indicating a conformational transition state at intermediate film areas 


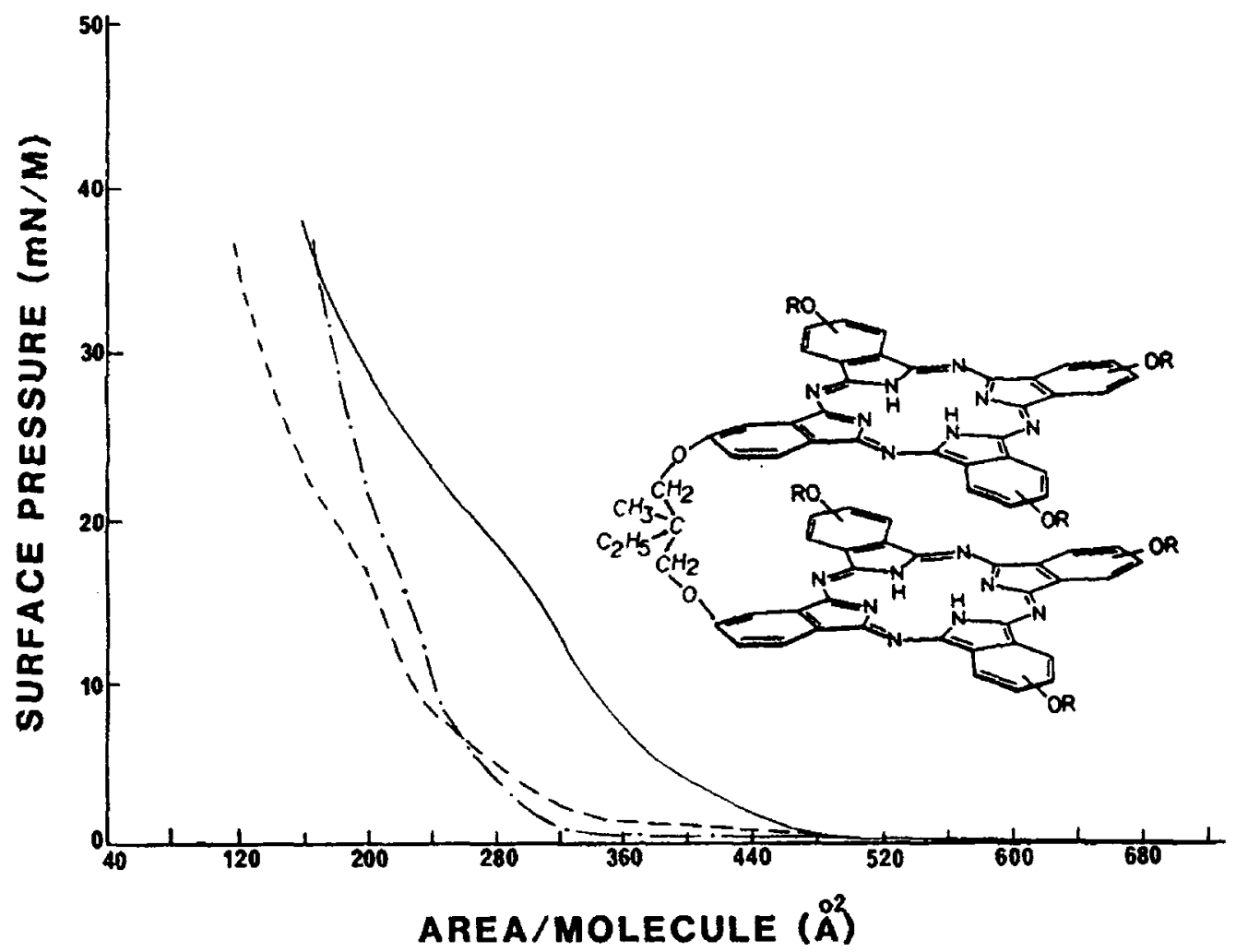

Fig. 3. Surface pressure-area isotherms of SG-C at various temperatures:,$- 13.3^{\circ} \mathrm{C}$; $-{ }^{-}-$, $22.3^{\circ} \mathrm{C} ;--, 31.6^{\circ} \mathrm{C}$.

(Fig. 3). This could be caused by a more extreme separation of the macrocycles which are now separated by a five member chain. A very large number of configurational states are possible in this structure. A similar shoulder, seen in the pressure region of $20-30 \mathrm{mN} \mathrm{m}^{-1}$, has been reported ${ }^{6}$ in the isotherm of copper octa(dodecoxymeythl) $\mathrm{Pc}^{6}$ and must relate to some restructuring process in the pendant side chains.

The effects of temperature were investigated (Table I); at the lowest temperature a somewhat more pronounced transition region can be seen. An equivalent effect can be seen in terms of the compression rate, the lower compression speed producing a smaller apparent molecular area. The SG-C molecule appears to have a flat orientation on the water surface, a condition favored by the extreme separation of the rings and the presence of the two oxygen atoms.

At present, it is not clear why other compounds studied in this series fail to show evidence of a shoulder in their isotherms.

\section{7. $S G-26 R$}

The linear trimer SG-26R is structurally a polymeric extension of SG-A, and its molecular area of about three times that of SG-A indicates that it, too, is oriented flat on the surface.

\subsection{SG-tet}

The variety of configurational states of this molecule again imply that a 
minimum molecular area may be achieved only at low compression rates. The measured molecular area would require a structure in which two macrocycles are lying flat on the surface, with the additional two oriented above, producing bilayer or other multilayer structures.

\section{CONCLUSIONS}

The monolayer behavior of substituted, multinucleate Pc structures is given here for the first time. The presence of two or more covalently bonded macrocycles in the same molecule greatly increases the number of configurational states possible and consequently will increase the complexity of events during monolayer compression. Although a number of plausible orientational states can be postulated on the basis of the isotherms measured, considerable additional characterization will be necessary before complete structural details are firmly established. To establish more completely the orientations of these systems as transferred Langmuir-Blodgett films, future studies will include ellipsometry and dichroic measurements.

\section{ACKNOWLEDGMENT}

The financial support of the U.S. Department of Energy, Chemical Sciences Division (DE-FG02-84ER13261), is gratefully acknowledged.

\section{REFERENCES}

1 S. Baker, M. C. Petty, G. G. Roberts and M. V. Twigg. Thin Solid Films, 99 (1983) 53.

2 H. Kuhn, Thin Solid Films, 99 (1983) 1.

D. Möbius, Acc. Chem. Res., 14 (1981) 63.

3 A. W. Snow and N. L. Jarvis, J. Am. Chem. Soc, 106 (1984) 4706.

4 S. M. Marcuccio, P. I. Svirskaya, S. Greenberg, A. B. P. Lever, C. C. Leznoff and K. B. Tomer, Can. J. Chem., 63 (1985) 3057.

S. Greenberg, S. M. Marcuccio, C. C. Leznoff and K. B. Tomer, Synthesis, (1986) 406.

5 C. J. Schramm, R. P. Scaringe, D. R. Stojakovic, B. M. Hoffman, J. A. Ibers and T. J. Marks, J. Am. Chem. Soc., 102 (1980) 6702 .

6 D. W. Kalina and S. W. Crane, Thin Solid Films, 134 (1985), 109.

7 J. Deisenhofer and H. Michel, Springer Ser. Chem. Phys., 42 (1985) 94. 